\title{
What Independence Is
}

\author{
Keith Burgess-Jackson
}

Correspondence: Keith Burgess-Jackson, J.D., Ph.D., Department of Philosophy and Humanities, College of Liberal Arts, The University of Texas at Arlington, Box 19527, Arlington, Texas, 76019-0527, USA. E-mail: kbj4@att.net, kbj@uta.edu

Received: July 8, 2020 Accepted: July 28, 2020 Online Published: August 10, 2020

doi:10.5539/res.v12n3p50 URL: https://doi.org/10.5539/res.v12n3p50

\begin{abstract}
Eighty years ago, in a short essay entitled "What Is Independence?," Richard Robinson (1902-1996) made two errors that, to my knowledge, remain uncorrected. The errors are (1) claiming that entailment entails consistency (it does not) and (2) misstating the relation of subcontrariness. To make good on my claim that these are errors, I present and explain, in a more systematic way than Robinson does, nine distinct logical relations, one of which is independence. There are independent reasons for making these relations - as well as their relations to one another-better known to philosophers.
\end{abstract}

Keywords: Alonzo Church (1903-1995), consistency, entailment, independence, logic, logical relations, non-entailment, non-subcontrariness, Richard Robinson (1902-1996), subcontrariness

A full understanding of relations will give the reader an accurate synoptic view of the province of logic (Cohen \& Nagel, 1934/1962: 56 [footnote omitted]).

\section{Introduction: Entailment and Non-Entailment}

Eighty years ago, in a brief but probing discussion in The Philosophical Review, English philosopher Richard Robinson (1902-1996), then teaching at Cornell University, made two errors that, to my knowledge, remain uncorrected (see Robinson, 1940). ${ }^{1}$ The errors, which occurred during a discussion of the ambiguity of the term "independence" (as used by logicians), are (1) claiming that entailment entails consistency and (2) misstating the relation of subcontrariness. To make good on my claim that these are errors, I shall present and explain, in a more systematic way than Robinson does, nine distinct logical relations, one of which is independence. There are independent reasons for making these relations - as well as their relations to one another - better known to philosophers.

Before presenting the relations, I must say a few words about the concepts of entailment and non-entailment. ${ }^{2}$ To say that proposition $\mathrm{p}$ entails proposition $\mathrm{q}$ is to say that it is logically impossible ${ }^{3}$ for $\mathrm{p}$ to be true while $\mathrm{q}$ is false, or, in symbols, ' $\sim \nabla(p \bullet \sim q)$ '. Letting ' $\rightarrow$ ' represent the entailment relation, we have ' $p \rightarrow q$ ', which is logically equivalent to $' \sim q \rightarrow \sim p '$ '. (Here again I anticipate our discussion of the nine logical relations, one of which is logical equivalence.)

Suppose we want to say that $\mathrm{p}$ does not entail q, i.e., that it is possible for $\mathrm{p}$ to be true while $\mathrm{q}$ is false. We have ' $\sim(\mathrm{p} \rightarrow$

${ }^{1}$ For information about Robinson's life and work, see Walter, 1996. Robinson's books include The Province of Logic (Robinson, 1931), Plato's Earlier Dialectic (Robinson, 1941), Definition (Robinson, 1950), An Atheist's Values (Robinson, 1964), and Essays in Greek Philosophy (Robinson, 1969). He also edited or translated three books on Aristotle.

${ }^{2}$ Entailment is simply logical implication, which is not to be confused with material implication. Proposition $\mathrm{p}$ materially implies proposition $q$ if and only if it is not the case that $p$ is true while $q$ is false. Proposition $p$ logically implies proposition $\mathrm{q}$ if and only if it cannot be the case that $\mathrm{p}$ is true while $\mathrm{q}$ is false. To say that $\mathrm{p}$ materially implies $\mathrm{q}$ is to say that ' $\sim(p \bullet \sim q)$ ' is true. To say that $\mathrm{p}$ logically implies $\mathrm{q}$ is to say that ' $\sim(\mathrm{p} \bullet \sim \mathrm{q})$ ' is necessarily true, i.e., a tautology. It is a necessary truth that if $\mathrm{p}$ logically implies $\mathrm{q}$, then $\mathrm{p}$ materially implies $\mathrm{q}$. It is not a necessary truth-indeed, it is false - that if $\mathrm{p}$ materially implies $\mathrm{q}$, then $\mathrm{p}$ logically implies $\mathrm{q}$. We might say (to anticipate our discussion of the nine logical relations, one of which is subalternation) that ' $p$ logically implies $q$ ' is the superaltern of ' $p$ materially implies q'. (Just as ' $x$ is the child of $y$ ' is the converse of ' $y$ is the parent of $x$ ', ' $p$ is the superaltern of q' is the converse of ' $q$ is the subaltern of $p$ '.)

${ }^{3}$ Henceforth, I omit the adverb "logically" in the expressions "logically possible" and "logically impossible," since it is clear that I am talking about logical possibility (impossibility) rather than, say, physical or psychological possibility (impossibility). 
q)', which is logically equivalent to ' $\sim(\sim \mathrm{q} \rightarrow \sim \mathrm{p})$ '. In stilted English, the first of these propositions says that it is not the case that $\mathrm{p}$ entails q. (The second proposition says that it is not the case that not-q entails not-p.) In mellifluous English, the first proposition says that $\mathrm{p}$ does not entail q. ${ }^{4}$ (The second proposition says that not-q does not entail not-p.) Using the modal operator for possibility, we get ' $\diamond(\mathrm{p} \bullet \sim \mathrm{q})$ '.

Suppose we want to say that $\mathrm{p}$ entails not-q. We have ' $\mathrm{p} \rightarrow \sim \mathrm{q}$ ', which is logically equivalent to ' $\mathrm{q} \rightarrow \sim \mathrm{p}$ '. If we wish to deny this, i.e., to say that $\mathrm{p}$ does not entail not-q, we get ' $\sim(\mathrm{p} \rightarrow \sim \mathrm{q})$ ', which is, of course, logically equivalent to ' $\sim(\mathrm{q} \rightarrow$ $\sim$ p)'.

Proceeding in this way through all the possibilities, we get the following jointly exhaustive and mutually exclusive list of entailments (rows 1 through 4) and non-entailments (rows 5 through 8):

\begin{tabular}{|l|l|l|l|l|}
\hline English Version & $\begin{array}{l}\text { Symbolic } \\
\text { Version }\end{array}$ & $\begin{array}{l}\text { Logically } \\
\text { Equivalent } \\
\text { to }\end{array}$ & Definition & $\begin{array}{l}\text { Modal } \\
\text { Version }\end{array}$ \\
\hline 1. $\mathrm{p}$ entails $\mathrm{q}$ & $\mathrm{p} \rightarrow \mathrm{q}$ & $\sim \mathrm{q} \rightarrow \sim \mathrm{p}$ & $\begin{array}{l}\text { It's impossible for } \mathrm{p} \text { to be true } \\
\text { while q is false. }\end{array}$ & $\sim \checkmark(\mathrm{p} \bullet \sim \mathrm{q})$ \\
\hline 2. $\mathrm{p}$ entails not-q & $\mathrm{p} \rightarrow \sim \mathrm{q}$ & $\mathrm{q} \rightarrow \sim \mathrm{p}$ & $\begin{array}{l}\text { It's impossible for both } \mathrm{p} \text { and } \mathrm{q} \\
\text { to be true. }\end{array}$ & $\sim \checkmark(\mathrm{p} \bullet \mathrm{q})$ \\
\hline 3. not-p entails $\mathrm{q}$ & $\sim \mathrm{p} \rightarrow \mathrm{q}$ & $\sim \mathrm{q} \rightarrow \mathrm{p}$ & $\begin{array}{l}\text { It's impossible for both } \mathrm{p} \text { and } \mathrm{q} \\
\text { to be false. }\end{array}$ & $\sim \checkmark(\sim \mathrm{p} \bullet \sim \mathrm{q})$ \\
\hline 4. not-p entails not-q & $\sim \mathrm{p} \rightarrow \sim \mathrm{q}$ & $\mathrm{q} \rightarrow \mathrm{p}$ & $\begin{array}{l}\text { It's impossible for } \mathrm{p} \text { to be false } \\
\text { while } \mathrm{q} \text { is true. }\end{array}$ & $\sim \checkmark(\sim \mathrm{p} \bullet \mathrm{q})$ \\
\hline 5. $\mathrm{p}$ does not entail $\mathrm{q}$ & $\sim(\mathrm{p} \rightarrow \mathrm{q})$ & $\sim(\sim \mathrm{q} \rightarrow \sim \mathrm{p})$ & $\begin{array}{l}\text { It's possible for } \mathrm{p} \text { to be true } \\
\text { while } \mathrm{q} \text { is false. }\end{array}$ & $\checkmark(\mathrm{p} \bullet \sim \mathrm{q})$ \\
\hline 6. $\mathrm{p}$ does not entail not-q & $\sim(\mathrm{p} \rightarrow \sim \mathrm{q})$ & $\sim(\mathrm{q} \rightarrow \sim \mathrm{p})$ & $\begin{array}{l}\text { It's possible for both } \mathrm{p} \text { and } \mathrm{q} \text { to } \\
\text { be true. }\end{array}$ & $\checkmark(\mathrm{p} \bullet \mathrm{q})$ \\
\hline 7. not-p does not entail $\mathrm{q}$ & $\sim(\sim \mathrm{p} \rightarrow \mathrm{q})$ & $\sim(\sim \mathrm{q} \rightarrow \mathrm{p})$ & $\begin{array}{l}\text { It's possible for both } \mathrm{p} \text { and } \mathrm{q} \text { to } \\
\text { be false. }\end{array}$ & $\checkmark(\sim \mathrm{p} \bullet \sim \mathrm{q})$ \\
\hline 8. not-p does not entail not-q & $\sim(\sim \mathrm{p} \rightarrow \sim \mathrm{q})$ & $\sim(\mathrm{q} \rightarrow \mathrm{p})$ & $\begin{array}{l}\text { It's possible for } \mathrm{p} \text { to be false } \\
\text { while q is true. }\end{array}$ & $\checkmark(\sim \mathrm{p} \bullet \mathrm{q})$ \\
\hline
\end{tabular}

Row 5 is the negation of row 1 ; row 6 is the negation of row 2 ; row 7 is the negation of row 3 ; row 8 is the negation of row 4. The column headings are (I assume) self-explanatory.

\section{Nine Logical Relations}

We are now in a position to define the nine logical relations, each of which is representable as either one row or a conjunction of two or more rows of the chart. Once this definitional task is completed, we will be able to see that (and perhaps why) Robinson erred in the two ways described in the opening paragraph.

The first of the nine logical relations is logical implication, i.e., entailment, which has already been discussed. If we limit ourselves to atomic propositions ('p' and ' $q$ '), we may say that entailment is representable as row 1 of the chart. (Rows 2, 3, and 4 contain at least one molecular proposition, namely, negation.)

The second and third relations are parasitic on the first. Suppose p entails q. Either q entails p or q does not entail p. If the first of these is the case, then $\mathrm{p}$ and $\mathrm{q}$ are logically equivalent. Logical equivalence (the relation) is bidirectional (i.e., two-way) entailment. If the second of these is the case, then $\mathrm{p}$ is the superaltern of q. Subalternation (the relation) is unidirectional (i.e., one-way) entailment.

Logical equivalence is representable as a conjunction of two rows of the chart, namely, 1 and 4 . To say that $\mathrm{p}$ is logically equivalent to $\mathrm{q}$ is to say two things: first, that $\mathrm{p}$ entails $\mathrm{q}$ (this is row 1); and second, that q entails $\mathrm{p}$ (this is row 4).

Subalternation is also representable as a conjunction of two rows of the chart, namely, 1 and 8 . To say that $\mathrm{p}$ is the superaltern of $\mathrm{q}$ (or, what comes to the same thing, that $\mathrm{q}$ is the subaltern of $\mathrm{p}$ ) is to say two things: first, that $\mathrm{p}$ entails $\mathrm{q}$ (this is row 1); and second, that q does not entail p (this is row 8).

That takes care of the first three of the nine relations. The fourth relation is contradictoriness. Proposition $\mathrm{p}$ is the contradictory of proposition $\mathrm{q}$ (i.e., $\mathrm{p}$ and $\mathrm{q}$ are contradictories [of one another]) if and only if (1) it is impossible for

${ }^{4}$ Compare: 'It is not the case that $\mathrm{x}$ is hungry' says (stiltedly) the same thing as ' $\mathrm{x}$ is not hungry'. 
both $\mathrm{p}$ and $\mathrm{q}$ to be true and (2) it is impossible for both $\mathrm{p}$ and $\mathrm{q}$ to be false. If we put this in terms of entailment, we get the following: first, $\mathrm{p}$ entails not-q (this is row 2); and second, not-p entails $\mathrm{q}$ (this is row 3). Contradictoriness, therefore, is representable as a conjunction of rows 2 and 3.

The fifth relation is contrariness. Proposition $\mathrm{p}$ is the contrary of proposition $\mathrm{q}$ (i.e., $\mathrm{p}$ and $\mathrm{q}$ are contraries [of one another]) if and only if (1) it is impossible for both $\mathrm{p}$ and $\mathrm{q}$ to be true and (2) it is possible for both $\mathrm{p}$ and $\mathrm{q}$ to be false. If we put this in terms of entailment, we get the following: first, p entails not-q (this is row 2); and second, not-p does not entail $\mathrm{q}$ (this is row 7). Contrariness, therefore, is representable as a conjunction of rows 2 and 7.

The sixth relation is subcontrariness. Proposition $\mathrm{p}$ is the subcontrary of proposition $\mathrm{q}$ (i.e., $\mathrm{p}$ and $\mathrm{q}$ are subcontraries [of one another]) if and only if (1) it is impossible for both $\mathrm{p}$ and $\mathrm{q}$ to be false and (2) it is possible for both $\mathrm{p}$ and $\mathrm{q}$ to be true. If we put this in terms of entailment, we get the following: first, not-p entails $q$ (this is row 3 ); and second, $p$ does not entail not-q (this is row 6). Subcontrariness, therefore, is representable as a conjunction of rows 3 and 6.

That takes care of relations four through six. The seventh relation is independence (the topic of Robinson's essay). Proposition $\mathrm{p}$ is independent of proposition $\mathrm{q}$ (i.e., $\mathrm{p}$ and $\mathrm{q}$ are independent [of one another]) if and only if (1) it is possible for $\mathrm{p}$ to be true while $\mathrm{q}$ is false; (2) it is possible for $\mathrm{q}$ to be true while $\mathrm{p}$ is false; (3) it is possible for both $\mathrm{p}$ and $\mathrm{q}$ to be true; and (4) it is possible for both $\mathrm{p}$ and $\mathrm{q}$ to be false. If we put this in terms of entailment, we get the following: first, $\mathrm{p}$ does not entail $\mathrm{q}$ (this is row 5); second, not-p does not entail not-q (this is row 8); third, p does not entail not-q (this is row 6); and fourth, not-p does not entail q (this is row 7). Independence, therefore, is representable as a conjunction of rows $5,8,6$, and 7 .

The eighth relation is consistency. Proposition $\mathrm{p}$ is consistent with proposition $\mathrm{q}$ (i.e., $\mathrm{p}$ and $\mathrm{q}$ are consistent [with one another]) if and only if it is possible for both $\mathrm{p}$ and $\mathrm{q}$ to be true. If we put this in terms of entailment, we get the following: p does not entail not-q (this is row 6). Consistency, therefore, is representable as row 6.

The ninth and final relation is inconsistency. Proposition $\mathrm{p}$ is inconsistent with proposition $\mathrm{q}$ (i.e., $\mathrm{p}$ and $\mathrm{q}$ are inconsistent [with one another]) if and only if it is impossible for both $\mathrm{p}$ and $\mathrm{q}$ to be true. If we put this in terms of entailment, we get the following: p entails not-q (this is row 2). Inconsistency, therefore, is representable as row 2.

Here is a summary of the nine logical relations:

\begin{tabular}{|l|l|}
\hline Logical Relation & Representable as Row(s) ... \\
\hline Logical Implication (i.e., Entailment) & 1 \\
\hline Logical Equivalence & 1 \& 4 \\
\hline Subalternation & $1 \& 8$ \\
\hline Contradictoriness & $2 \& 3$ \\
\hline Contrariness & $2 \& 7$ \\
\hline Subcontrariness & $3 \& 6$ \\
\hline Independence & $5,6,7, \& 8$ \\
\hline Consistency & 6 \\
\hline Inconsistency & 2 \\
\hline
\end{tabular}

One virtue of this representational device is that it enables us to "see" how various relations are related to one another. Logical equivalence entails entailment, for example (since ' 1 \& 4' entails ' 1 '), but not conversely. Subalternation entails entailment (since ' $1 \& 8$ ' entails ' 1 '), but not conversely. Both contradictoriness and contrariness entail inconsistency (since both ' $2 \& 3$ ' and ' $2 \& 7$ ' entail ' 2 '), but not conversely. Both subcontrariness and independence entail consistency (since both ' $3 \&$ ' 6 ' and ' $5,6,7, \&$ ' entail ' 6 '), but not conversely. 
The information contained in the representational device is also incorporated in the following flowchart (with names of relations in boldface type):

\begin{tabular}{|c|c|c|c|c|c|c|}
\hline \multicolumn{7}{|c|}{ Is it possible for $p$ to be true while $q$ is false? } \\
\hline \multicolumn{5}{|c|}{ Yes. Is it possible for $\mathrm{q}$ to be true while $\mathrm{p}$ is false? } & \multicolumn{2}{|c|}{$\begin{array}{l}\text { No. Then } p \text { entails } q \text {. Is it } \\
\text { possible for q to be true while } \\
\text { p is false? }\end{array}$} \\
\hline \multicolumn{4}{|c|}{ Yes. Is it possible for both $\mathrm{p}$ and $\mathrm{q}$ to be true? } & $\begin{array}{l}\text { No. Then q is } \\
\text { the } \\
\text { superaltern } \\
\text { of p. }\end{array}$ & $\begin{array}{l}\text { Yes. Then } p \\
\text { is the } \\
\text { superaltern } \\
\text { of q. }\end{array}$ & $\begin{array}{l}\text { No. Then } p \text { is } \\
\text { logically } \\
\text { equivalent to } \\
\text { q. }\end{array}$ \\
\hline \multicolumn{2}{|c|}{$\begin{array}{l}\text { Yes. Then } \mathrm{p} \text { is consistent } \\
\text { with q. Is it possible for both } \\
\mathrm{p} \text { and q to be false? }\end{array}$} & \multicolumn{2}{|c|}{$\begin{array}{l}\text { No. Then } \mathrm{p} \text { is inconsistent } \\
\text { with q. Is it possible for both } \mathrm{p} \\
\text { and q to be false? }\end{array}$} & & & \\
\hline $\begin{array}{l}\text { Yes. Then } p \\
\text { is } \\
\text { independent } \\
\text { of q. }\end{array}$ & $\begin{array}{l}\text { No. Then } \mathrm{p} \text { is } \\
\text { the } \\
\text { subcontrary } \\
\text { of q. }\end{array}$ & $\begin{array}{l}\text { Yes. Then } p \\
\text { is the } \\
\text { contrary of } \\
\text { q. }\end{array}$ & $\begin{array}{l}\text { No. Then } \mathrm{p} \text { is } \\
\text { the } \\
\text { contradictory } \\
\text { of } q .\end{array}$ & & & \\
\hline
\end{tabular}

Ten relations (rather than nine) are represented in the flowchart. The reason for this is that the relation of subalternation appears twice, once for the case in which $\mathrm{p}$ is the superaltern of $\mathrm{q}$ and again for the case in which $\mathrm{q}$ is the superaltern of $\mathrm{p}$.

\section{Two Conceptions of Independence}

Let us (re)turn to Robinson's essay on independence, for we are now in a position to diagnose and treat (i.e., to identify and correct) his errors. Robinson sets out his objectives in the first paragraph: "I shall first show that in logic we use the word 'independence' in two different senses; and then propose a change of terminology to avoid this ambiguity" (Robinson, 1940: 355). The first use of "independence" (call it independence ${ }_{1}$ ) corresponds to that given above (in Part 2), though Robinson uses different terminology than I do. Independence ${ }_{1}$, he says, is a conjunction of (1) non-entailment, (2) consistency, and (3) non-subcontrariness.

Two propositions stand in the relation of non-entailment when neither of them entails the other. This corresponds to the conjunction of rows 5 and 8 of my chart. Two propositions stand in the relation of consistency when neither of them entails the negation of the other. This corresponds to row 6 of my chart. Two propositions stand in the relation of non-subcontrariness when neither of their negations entails the (unnegated) other. This corresponds to row 7 of my chart. Since independence ${ }_{1}$ is the conjunction (Robinson says) of non-entailment, consistency, and non-subcontrariness, it is the conjunction of rows 5, 8, 6, and 7 of my chart, which is precisely how I defined "independence" in Part 2.

Independence ${ }_{2}$ is what Robinson calls non-entailment, which, as we just saw, corresponds to the conjunction of rows 5 and 8 of my chart.

The problem Robinson identifies is this. Logicians routinely say that any proposed set of axioms or postulates (hereafter "postulates") must be both independent and consistent, but which sense of "independence" do they have in mind when

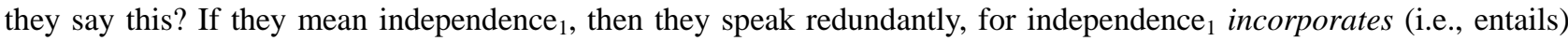
consistency. If they mean independence $e_{2}$, then they omit non-subcontrariness. To put it as perspicuously as I can:

- $\quad$ Independence $_{1}=$ non-entailment (rows 5 and 8), consistency (row 6), and non-subcontrariness (row 7).

- Independence ${ }_{2}=$ non-entailment (rows 5 and 8).

If we say that a set of postulates must be both independent ${ }_{1}$ and consistent, we are saying that it must have the properties of non-entailment, consistency, non-subcontrariness, and consistency, which is redundant ("consistency" being listed twice). If we say that a set of postulates must be both independent ${ }_{2}$ and consistent, we are saying that it must have the properties of non-entailment and consistency, which omits the property of non-subcontrariness. (Two or more propositions stand in the relation of non-subcontrariness, according to Robinson, when it is possible for all of them to be false. I shall criticize this terminology shortly.)

There are two possible solutions of the problem, according to Robinson. First, we can say that a set of postulates must be, simply, independent ${ }_{1}$ (omitting consistency from the list); second, we can say that a set of postulates must stand in the relations of independence ${ }_{2}$, consistency, and non-subcontrariness. Robinson plumps for the former. "[I]nstead of saying that 'postulate-sets must be both consistent and independent', we should say that 'postulate-sets must be independent, and independence includes both [sic] consistency and non-subcontrariness and non-entailment"” (Robinson, 1940: 356 [third 
and fourth hyphens added for the sake of uniformity]). ${ }^{5}$

\section{Robinson's Two Errors}

I said at the outset that Robinson makes two errors. Both errors, fortunately for him, are harmless, in the sense that they do not undermine his central thesis; but they ought to be corrected nonetheless. (As in law, a harmless error - even a harmless error that has remained unnoticed or uncorrected for a long time- is still an error.) The first error concerns the relation between non-entailment and consistency. Robinson points out (though not in the same way I do) that cells 1, 3, and 4 of the following diagram are exemplified (Robinson, 1940: 355):

\begin{tabular}{|c|c|c|}
\hline & $\begin{array}{l}\text { Consistency (i.e., it is possible for } \\
\text { both p and q to be true) }\end{array}$ & $\begin{array}{l}\text { Inconsistency (i.e., it is impossible } \\
\text { for both } \mathrm{p} \text { and } \mathrm{q} \text { to be true) }\end{array}$ \\
\hline $\begin{array}{l}\text { Entailment (i.e., either p entails q or } \\
\text { q entails p, or both) }\end{array}$ & ( & ( \\
\hline $\begin{array}{l}\text { Non-entailment (i.e., p does not } \\
\text { entail q and q does not entail p) }\end{array}$ & 3 & 4 \\
\hline
\end{tabular}

An example of cell 1, according to Robinson, is the pair of propositions ' $x$ is red' and ' $x$ is colored'. (The former entails the latter; both can be true.) An example of cell 3 is the pair of propositions ' $x$ is red' and ' $x$ is large'. (Neither entails the other; both can be true.) An example of cell 4 is the pair of propositions ' $x$ is all red' and ' $x$ is all green'. (Neither entails the other; it's not the case that both can be true.)

Robinson claims that cell 2 has no members. He writes:

\footnotetext{
${ }^{5}$ In a one-paragraph "review" of Robinson's two-page essay, Alonzo Church (1940: 81) suggests a third solution, namely, letting "independence" mean independence, while substituting "complete independence" for independence ${ }_{1}$. If I understand Church correctly, he wishes to disambiguate the ambiguous term "independence" by increasing the number of terms (adding "complete independence" to "independence"). Robinson, by contrast, wishes to disambiguate the ambiguous term "independence" by offering a precising definition of "independence."

Church wants to continue saying that a set of postulates must be both independent and consistent. He proposes letting "independence" mean what Robinson calls "non-entailment." But notice: a list consisting of non-entailment and consistency omits what Robinson calls "non-subcontrariness." I think Church is content with this omission. We want two things (he would say) from a set of postulates. First, we want no member of the set to be entailed by any other (or by a conjunction of others). This is non-entailment. Second, we want it to be possible for all members of the set to be true. This is consistency. Why should we care (Church would say) whether it is possible for all members of the set to be false? If we don't care about this, then we don't care about non-subcontrariness, and if we don't care about non-subcontrariness, then why should we add it to our list of requirements for postulate-sets?
}

I imagine the following exchange between Robinson and Church:

Robinson: The word "independence," as used by logicians, is ambiguous. This is problematic, because it generates (or is liable to generate) confusion. Let us, therefore, disambiguate the term "independence" by agreeing to use it to mean the conjunction of non-entailment, consistency, and non-subcontrariness. One virtue of this precising definition is that mathematical logicians won't have to keep saying that sets of postulates must be independent and consistent, for consistency is baked into the (proposed) concept of independence.

Church: This won't do, because mathematical logicians don't need, and therefore (given Ockham's Razor) don't want, the relation of subcontrariness. While mathematical logicians care whether it's possible for a set of postulates to be true (since, if it isn't possible, there must be at least one false postulate), we don't care whether it's possible for a set of postulates to be false (for all that would show is that there must be at least one true postulate). So let me make a counterproposal. Let mathematical logicians continue to use the term "independence" to mean non-entailment. They can then say, when speaking of sets of postulates, that such sets must be independent and consistent. Since your concept of independence differs from ours, and since both of us wish to avoid confusion brought on by ambiguity, why don't you call your four-part conception of independence "complete independence"? Problem solved.

To summarize, complete independence (as Church would have it) is the conjunction of non-entailment ( $\mathrm{p}$ does not entail $\mathrm{q}$ and $\mathrm{q}$ does not entail p), consistency (both $\mathrm{p}$ and $\mathrm{q}$ may be true), and non-subcontrariness (both $\mathrm{p}$ and $\mathrm{q}$ may be false). (I call this a four-part concept rather than a three-part concept because non-entailment is itself a two-part concept.) Independence (as Church would have it) is simply non-entailment ( $p$ does not entail $q$ and $q$ does not entail $p$ ). A set of postulates, Church would say, must be both independent (in the proposed sense) and consistent. 
There are no propositions standing neither in the relation of non-entailment nor in that of consistency; for, if they do not stand in the relation of non-entailment, one of them entails the other and hence they are consistent (Robinson, 1940: 355 [hyphens added for the sake of uniformity]).

Robinson's claim is false. There are, in fact, propositions standing neither in the relation of non-entailment nor in that of consistency. To take just one example, consider ' $\mathrm{p} \bullet \sim \mathrm{p}$ ' and ' $\mathrm{p}$ '. The first proposition is the superaltern of the second, which means that the first proposition entails, but is not entailed by, the second. According to Robinson, two propositions stand in the relation of non-entailment when neither entails the other. Since ' $p \bullet \sim p$ ' entails ' $p$ ', the propositions do not stand in the relation of non-entailment.

The propositions ' $p \bullet \sim p$ ' and ' $p$ ' are also inconsistent (with one another), in the sense that it is impossible for both to be true. ${ }^{6}$ So, pace Robinson, there are propositions standing neither in the relation of non-entailment nor in that of consistency. This can be seen in another way as well. Robinson says, at the end of the quoted passage, that "one of [the propositions] entails the other and hence they are consistent" (Robinson, 1940: 355 [italics added]). I have provided a counterexample to this claim, to wit: 'p $\bullet \sim p$ ' entails 'p', but the two propositions are not consistent (with one another).

Robinson's second error, which is equally harmless but no less worthy of correction, concerns the relation of subcontrariness. He writes:

It may happen that not-p entails $q$. When this is so I say that $p$ and $q$ are 'subcontrary', following logical usage. When not-p does not entail q, I say that $p$ and $q$ are 'non-subcontrary' (Robinson, 1940:

355 [italics omitted; final hyphen added for the sake of uniformity]).

In Part 2 of this essay, where I discussed the nine logical relations, I wrote that "proposition $p$ is the subcontrary of proposition q (i.e., p and q are subcontraries [of one another]) if and only if (1) it is impossible for both $p$ and $q$ to be false and (2) it is possible for both $\mathrm{p}$ and $\mathrm{q}$ to be true." This two-part definition has been standard in the literature for more than a century. ${ }^{7}$ If we put the two-part definition in terms of entailment or non-entailment rather than possibility or impossibility, we get the following: first, not-p entails q (this is row 3 of my chart); and second, p does not entail not-q (this is row 6 of my chart). Subcontrariness, therefore, is representable as a conjunction of rows 3 and 6 of my chart. Robinson represents it as row 3 simpliciter. ${ }^{8}$

Why does this matter? It matters because, if subcontrariness is representable as row 3 of my chart, then non-subcontrariness (its negation) is representable as row 7. (Recall that rows 1 through 4 list entailments and rows 5 through 8 non-entailments. Row 7 is the negation of row 3.) This is exactly how Robinson understands it: as row 7. But if, as accords with "logical usage," subcontrariness is representable as the conjunction of rows 3 and 6 , then

${ }^{6}$ This can be shown by means of a truth table. Here is the verbal version: Proposition ' $p$ ' is either true or false. If ' $p$ ' is true, then the second of the two propositions is true, but the first false. If ' $p$ ' is false, then both propositions are false. There is, therefore, no assignment of truth values to the atomic propositions in which both propositions (the first of which is molecular, the second atomic) are true.

7 See, e.g., Joseph, 1916: 230 ("Sub-contrary propositions cannot both be false . . .; but they may both be true") (italics in original); Cohen \& Nagel, 1934/1962: 55 ("In this case, both propositions cannot be false, but both may be true. Such propositions are called subcontraries") (italics in original); Stebbing, 1950: 58 ("The propositions $p$ and $q$ may be so related that if $p$ is false, $q$ is true, and if $q$ is false, $p$ is true, while both may be true. The excluded case is that of the falsity of both $p$ and $q$. In this case $p$ and $q$ are said to be subcontraries, and the relation holding between them is called subcontrariety") (italics in original); Copi, 1953: 133 ("Two propositions are said to be subcontraries if they cannot both be false, though they might both be true") (italics in original); Brody, 1967: 75 ("subcontrary propositions. Two propositions that cannot both be false but may both be true") (boldface in original); Baronett, 2019: 217 ("The flip side of contraries are subcontraries, which ... cannot both be false at the same time, but can both be true at the same time") (boldface in original).

Strawson (1952: 25) provides a one-part definition: "Two statements are contraries when it is logically impossible for them both to be true; subcontraries when it is logically impossible for them both to be false." One unfortunate consequence of Strawson's definition is that a single pair of propositions (e.g., 'p' and ' $\sim$ p') may simultaneously stand in the relations of contrariness, subcontrariness, and contradictoriness. Indeed, contradictoriness, on his understanding, is the conjunction of contrariness and subcontrariness!

${ }^{8}$ Near the end of his essay, Robinson writes: "Even when neither p nor q entails the truth of the other, these two propositions may fail to be independent in the common sense; for one may entail the falsity of the other, which is inconsistency, or the falsity of one may entail the truth of the other, which is subcontrariness. .." (Robinson, 1940: 356 [italics added]). He should have said "which is half of subcontrariness." 
non-subcontrariness (its negation) is (by De Morgan's Theorem) representable as the disjunction of the negations of rows 3 and 6 . Since the negation of row 3 is row 7, and since the negation of row 6 is row 2, non-subcontrariness is representable as either row 7 or row 2. It is not, as Robinson says, representable as row 7.

The reason this error is harmless, in the context of Robinson's essay, is that Robinson need not have used any term at all to describe the relation in which two propositions may both be false. He calls this relation "non-subcontrariness," but he might well have called it "falsiness." The substance of Robinson's claim — which is correct—is that independence ${ }_{1}$ is a conjunction of four claims. Proposition $\mathrm{p}$ is independent $t_{1}$ of proposition $\mathrm{q}$ (i.e., $\mathrm{p}$ and $\mathrm{q}$ are independent ${ }_{1}$ [of one another]) if and only if (1) it is possible for $\mathrm{p}$ to be true while $\mathrm{q}$ is false; (2) it is possible for $\mathrm{q}$ to be true while $\mathrm{p}$ is false; (3) it is possible for both p and q to be true; and (4) it is possible for both p and q to be false. Robinson calls the conjunction of claims 1 and 2 "non-entailment." He calls claim 3 "consistency." He calls claim 4 "non-subcontrariness." I have argued that Robinson's use of the term "subcontrariness" was not then, and is not now, in accordance with "logical usage."

\section{Conclusion: Logic as the Study of Relations Between Propositions}

The nine logical relations discussed in this essay, together with their relations to one another, deserve greater attention in the philosophical literature, including in logic textbooks. Every textbook that I have used or examined in 37 years of teaching contains a discussion of some subset of the relations, but no textbook of which I am aware presents all nine of them, and certainly no textbook presents them systematically, as I have. Most logic textbooks focus on the concept of argumentative validity and address the logical relations haphazardly, as they come up in discussion of other topics. If my approach were adopted by textbook writers, the nine logical relations would form the core of deductive logic (see the epigraph), and validity would be understood as a special case of one relation, namely, entailment. A valid argument is simply an argument the conjoined premises of which entail its conclusion.

\section{Acknowledgements}

This essay is dedicated to the memory of Irving Marmer Copi (1917-2002): gentleman, scholar, benefactor, and friend.

\section{References}

Baronett, S. (2019). Logic (4th ed.). New York, NY: Oxford University Press.

Brody, B. A. (1967). Logical terms, glossary of. In P. Edwards (Ed.), The encyclopedia of philosophy (vol. 5, pp. 57-77). New York, NY: Macmillan.

Church, A. (1940). Review of "What Is Independence?" The Journal of Symbolic Logic, 5(2), 81. https://doi.org/10.2307/2266203

Cohen, M. R., \& Nagel, E. (1934/1962). An introduction to logic. New York, NY: Harcourt, Brace \& World.

Copi, I. M. (1953). Introduction to logic. New York, NY: Macmillan.

Joseph, H. W. B. (1916). An introduction to logic (2nd ed., rev.). Oxford, UK: Clarendon Press.

Robinson, R. (1931). The province of logic: An interpretation of certain parts of Cook Wilson's "Statement and Inference. " London, UK: Routledge.

Robinson, R. (1940). What is independence? The Philosophical Review, 49(3), 355-356. https://doi.org/10.2307/2180872

Robinson, R. (1941). Plato's earlier dialectic. Ithaca, NY: Cornell University Press.

Robinson, R. (1950). Definition. Oxford, UK: Clarendon Press.

Robinson, R. (1964). An atheist's values. Oxford, UK: Clarendon Press.

Robinson, R. (1969). Essays in Greek philosophy. Oxford, UK: Clarendon Press.

Stebbing, L. S. (1950). A modern introduction to logic (7th ed.). London, UK: Methuen.

Strawson, P. F. (1952). Introduction to logical theory. London, UK: Methuen.

Walter, N. (1996, June 14). Obituary: Richard Robinson. Independent (UK edition). https://www.independent.co.uk/news/people/obituary-richard-robinson-5612006.html

\section{Copyrights}

Copyright for this article is retained by the author(s), with first publication rights granted to the journal.

This is an open-access article distributed under the terms and conditions of the Creative Commons Attribution license (http://creativecommons.org/licenses/by/4.0/). 